\title{
Adherence to the Mediterranean Diet and Determinants Among Pregnant Women: The NELA Cohort
}

\author{
Clara Suárez-Martínez ${ }^{1,2}\left(0\right.$, Genoveva Yagüe-Guirao ${ }^{1,3}$, Marina Santaella-Pascual ${ }^{1,2}$, Patricia Peso-Echarri ${ }^{1,2}$, \\ Jesús Vioque ${ }^{4,5}$, Eva Morales ${ }^{1,6}$, Luis García-Marcos ${ }^{1,7}$ (D) Carmen Martínez-Graciá ${ }^{1,2, *(1)}$ \\ and The NELA Study Group ${ }^{\dagger}$
}

check for updates

Citation: Suárez-Martínez, C.; Yagüe-Guirao, G.; Santaella-Pascual, M.; Peso-Echarri, P.; Vioque, J.; Morales, E.; García-Marcos, L.; Martínez-Graciá, C.; Adherence to the Mediterranean Diet and Determinants Among Pregnant Women: The NELA Cohort. Nutrients 2021, 13, 1248. https://doi.org/ $10.3390 /$ nu13041248

Academic Editor: Tiziana Montalcini

Received: 16 March 2021

Accepted: 7 April 2021

Published: 10 April 2021

Publisher's Note: MDPI stays neutral with regard to jurisdictional claims in published maps and institutional affiliations.

Copyright: (c) 2021 by the authors. Licensee MDPI, Basel, Switzerland. This article is an open access article distributed under the terms and conditions of the Creative Commons Attribution (CC BY) license (https:// creativecommons.org/licenses/by/ $4.0 /)$.
1 Biomedical Research Institute of Murcia (IMIB-Arrixaca), 30120 Murcia, Spain; clara.suarez@um.es (C.S.-M.); gyague@um.es (G.Y.-G.); marinasp@um.es (M.S.-P.); patri.peso@um.es (P.P.-E.); evamorales@um.es (E.M.); lgmarcos@um.es (L.G.-M.)

2 Food Science and Nutrition Department, Veterinary Faculty, CEIR Campus Mare Nostrum (CMN), University of Murcia, 30100 Murcia, Spain

3 Microbiology Service, Virgen de La Arrixaca University Clinical Hospital, CEIR Campus Mare Nostrum (CMN), University of Murcia, 30120 Murcia, Spain

4 Health and Biomedical Research Institute of Alicante (ISABIAL-UMH), 46020 Alicante, Spain; vioque@umh.es

5 Spanish Consortium for Research on Epidemiology and Public Health (CIBERESP), 28029 Madrid, Spain

Department of Public Health Sciences, University of Murcia, 30100 Murcia, Spain

7 Paediatric Allergy and Pulmonology Units, Virgen de La Arrixaca University Clinical Hospital, ARADyAL Allergy Network, CEIR Campus Mare Nostrum (CMN), University of Murcia, 30120 Murcia, Spain

* Correspondence: mamen@um.es; Tel.: +34-868-888263

+ Members of the NELA study group is provided in the Acknowledgments.

\begin{abstract}
The Mediterranean diet represents one of the most studied dietary patterns; however, there is no single tool for measuring the grade of adherence and no single set of criteria for adapting these indices to pregnant women. We characterized the adherence to the Mediterranean diet (MDA) of pregnant women participating in the NELA (Nutrition in Early Life and Asthma) cohort and identified the sociodemographic determinants and lifestyle habits associated with a higher risk of a low MDA. Maternal diet during gestation was assessed by a validated Food Frequency Questionnaire (FFQ) $(n=665)$. We estimated the Relative Mediterranean Diet score (rMED), Alternative Mediterranean Diet score (aMED), and the Alternate Healthy Eating Index-2010 (AHEI-2010). Multivariate regression models were performed to identify the sociodemographic and lifestyle factors associated with each index. Mothers with a lower age and more previous deliveries had a greater probability of low MDA $(p<0.05)$. For the aMED index only, mothers with university education and/or who practiced sport activities for two or more hours per week had a lower probability of a low MDA $(p<0.01)$. The three indices classified the NELA cohort as having a medium level of adherence. These results may be improved by designing intervention strategies and dietary recommendations for both maternal and offspring health.
\end{abstract}

Keywords: dietary pattern; Mediterranean diet; healthy diet; pregnancy; lifestyle; sociodemographic factors

\section{Introduction}

The period of prenatal life is considered to be a critical window for both the mother's and offspring's health; in particular, the maternal diet during pregnancy has been proposed as one of the prenatal factors that has long-term implications and influences on the development of the placenta [1] and on the risk of developing gestational diabetes [2]. The prenatal diet is also associated with complications at birth including premature birth $[3,4]$, pre-eclampsia [5], low birth weight [3], and it may influence the correct development and response of the foetal immune system and consequently the risk of developing allergies 
or asthma in childhood [6-10]. In addition, during pregnancy, maternal Mediterranean diet adherence (MDA) may promote behavioral and emotional wellbeing in children [11]. Traditionally, the isolated effects of foods or specific nutrients consumed during pregnancy on health and their possible role in the development of diseases in offspring have been investigated. However, this type of analysis can omit relevant information and be inaccurate since foods are consumed together in the context of a diet, creating synergies between them $[12,13]$.

The Mediterranean diet (MD) and Mediterranean diet adherence (MDA) have been investigated due to its beneficial effects and protective role against diseases, demonstrated in numerous high-quality studies, reviews [6,14,15], and meta-analyses [16-19], making it the most widely studied and evidence-based dietary approach to healthy eating and disease prevention $[17,19,20]$. One of the last and most correct definitions of the MD during pregnancy is the one described by Amati et al. [21] in their review in 2019. The authors described the MD as a "diet characterized by a high intake of fruits, vegetables, whole grain cereals and bread, legumes, fish and nuts; low-to-moderate consumption of dairy products and eggs, and limited amounts of red meat and red wine. It is low in saturated fats and high in antioxidants, fibre and mono and polyunsaturated fatty acids (MUFAs and PUFAs) mainly derived from extra virgin olive oil and oily fish (n-3 PUFAs)". Beyond nutritional guidelines, the MD represents a balanced and healthy lifestyle that includes physical activity, adequate rest, traditional and simple ways of cooking, and sociability at the table as the main habits registered in the latest available edition of the Pyramid of MD, published by the Mediterranean Diet Foundation [22]. Olmeda-Requena et al. in 2014 [23] carried out a research to study the factors associated with a low adherence to an MD pattern in healthy women and concluded that a younger age, a low social class, a low educational level, and an unhealthy lifestyle (smoking and lack of exercise) were associated with a low MDA.

Trichopoulou et al. in 2003 [24] were the first researchers to quantify MDA using a 10-point numerical scale, which is the well-known Mediterranean Diet Score (MDS). They reported an inverse association between the score obtained and total mortality. The higher the MDA, the lower the mortality rate, both from coronary heart disease and cancer. In relation to the numerous indices that have been developed to measure the MDA in the adult population, Olmedo-Requena et al. [25] studied the degree of correlation between the five different indices that have been developed to date and applied to the same population (healthy adults), concluding that concordance between them (including the Relative Mediterranean Diet score (rMED) and Alternative Mediterranean Diet score (aMED)) was moderate or low. The authors reported the existence of a different classification of the subjects due to variations in the food groups included.

Furthermore, in most of the cohorts that study the pattern of adherence to the MD of adults or pregnant women, a single index has been used, and there is no consensus when applying one or the other index. To date, no comparison has been made of the two most widely used scores (rMED and aMED), applied to the same population of pregnant women or the sociodemographic and lifestyle factors that influence this degree of adherence to check if the same conclusions are reached-this being a complementary objective of this work.

The aims of this study were to evaluate the adherence to the MD in pregnant women of the NELA study (Nutrition in Early Life and Asthma), a prospective birth cohort study established in the Mediterranean Region of Murcia (Spain), and to identify lifestyles and sociodemographic factors associated with a low MDA.

\section{Materials and Methods}

\subsection{Study Population}

The Nutrition in Early Life and Asthma (NELA) birth cohort study recruited 738 pregnant women between 2015 and 2018 in Murcia, a south-eastern Mediterranean region of Spain (www.nela.imib.es). The main objective of NELA is to unravel the developmental 
origins and mechanisms of asthma and allergy. Recruitment took place at the time of the control ultrasound at 20 weeks of gestation at the Maternal-Fetal Unit of the Virgen de la Arrixaca University Hospital. The inclusion criteria were women from Health Area I and certain districts of Health Areas VI and VII of the Region of Murcia; planning to live in the area of study for at least 2 years; the intention to give birth at the reference hospital; Spanish Caucasian origin; $18-45$ years of age; singleton pregnancy; non-assisted conception; and normal echography at 20 weeks of gestation (no major malformations). The exclusion criteria included an existing chronic disease; pregnancy complications (except gestational diabetes and hypertensive disorders); and not intending to deliver in the reference hospital. Among the 1350 women invited to participate, 738 (54\%) were finally enrolled in the study, of which 665 completed the dietary information

The study protocol was reviewed and approved by the Ethics Committee of the Virgen de la Arrixaca University Clinical Hospital in accordance with the guidelines of The Declaration of Helsinki. Written informed consent was obtained from parents at recruitment.

\subsection{Maternal Dietary Intake Assessment and Development of Mediterranean Diet Scores}

The dietary information on usual daily food intake was collected at 20 weeks of gestation, using a Food Frequency Questionnaire (FFQ) previously validated among pregnant women of the INfancia y Medio Ambiente-(environment and childhood) (INMA) prospective cohort study [26] which was administered by trained interviewers. The FFQ included 123 items, of which 112 were semi-quantitative, to assess usual food and nutrient intakes during the first 20 weeks of gestation, and 11 qualitative to collect information about the use of dietary supplements and organic food consumption. For each food item, the questionnaire asked how often, on average, the participants had consumed a particular amount of specific type of food from the beginning of pregnancy until the time of the interview. For each food item, standard units or reference serving sizes were specified. The questionnaire had nine possible intake frequency categories, ranging from "less than once per month or never" to " 6 or more times per day". Nutrient values and energy intakes were obtained from the US Department of Agriculture Food Composition Tables [27], as well as other published sources for Spanish foods, portion sizes, and their content for some specific nutrients such as folic acid [28,29]. The intake frequency for each food item was converted to the average daily intake for each participant. For the calculation of the different scores in each of the dietary patterns described below, the consumption of vitamin or mineral supplements by the mother during pregnancy was not considered.

\subsection{Diet Quality Scores}

To evaluate the degree of adherence to the MD during pregnancy, we used two scores: the Alternative Mediterranean Diet score (aMED [30]) and the Relative Mediterranean Diet score (rMED [31]); both are a modified version of the Mediterranean Diet Score (MDS) proposed by Trichopoulou and colleagues in 1995 [32]. As Chatzi et al. reported in different publications $[7,33]$, we did not include alcohol consumption to calculate the scores because the population in the present study involved pregnant women and both scores had been developed for adults. Table 1 shows the main items of each of the scores used to determine adherence to MD, as well as their main differences.

The relative Mediterranean Diet score (rMED) was proposed by Bukcland et al. (2009) for the European Prospective Investigation into Cancer and Nutrition (EPIC)-Spain cohort [31]. This indicator has eight components (originally nine, but alcohol was excluded): vegetables (excluding potatoes), fruits, nuts and seeds (but excluding fruit juices), cereals (including whole grain, refined flour, pasta, rice, and bread), legumes, fish and seafood, dairy products (including low and high fat products, cheese, yogurt, and cream desserts), total meat (including white, red, and processed meat), and olive oil. In addition, before assigning the scores to the rMED groups (except alcohol), the intakes were transformed into grams per $1000 \mathrm{Kcals} /$ day. To assign the scores, tertiles were used instead of the medium, and the values 0,1 , and 2 were assigned to the first, second, and third tertiles of 
intake, except for meats and dairy products that were assigned to the contrary, the highest tertile being scored with a 0 . The possible scores ranged from 0 units (minimal adherence) to 16 units (maximum adherence). An rMED score of $0-5$ was labelled as "low", 6-11 as "medium", and 12-16 as "high" MD adherence by calculating the corresponding tertiles.

Table 1. Characteristics of Mediterranean diet adherence pattern indexes applied in pregnancy.

\begin{tabular}{|c|c|c|}
\hline Food Groups & $\begin{array}{c}\text { Alternative Mediterranean } \\
\text { Score (aMED) }\end{array}$ & $\begin{array}{l}\text { Relative Mediterranean } \\
\text { Score (rMED) }\end{array}$ \\
\hline Scoring criteria & Ratios/day & $\begin{array}{c}\text { Energy density }=g^{*} 1000 \\
\text { Kcal/day }\end{array}$ \\
\hline Vegetables & $\begin{array}{l}0 \text { points } \leq \text { median; } \\
1 \text { point }>\text { median }\end{array}$ & $\begin{array}{l}\text { Tertile } 1=0 \text { points; } \\
\text { Tertile } 2=1 \text { point; } \\
\text { Tertile } 3=2 \text { points }\end{array}$ \\
\hline Legumes & $\begin{array}{l}0 \text { points } \leq \text { median; } \\
1 \text { point }>\text { median }\end{array}$ & $\begin{array}{l}\text { Tertile } 1=0 \text { points; } \\
\text { Tertile } 2=1 \text { point; } \\
\text { Tertile } 3=2 \text { points }\end{array}$ \\
\hline Fruit & $\begin{array}{l}0 \text { points } \leq \text { median; } \\
1 \text { point }>\text { median }\end{array}$ & $\begin{array}{l}\text { (excluding fruit juice) } \\
\text { Tertile } 1 \text { = } 0 \text { points; } \\
\text { Tertile } 2 \text { = } 1 \text { point; } \\
\text { Tertile } 3=2 \text { points }\end{array}$ \\
\hline Nuts & $\begin{array}{l}0 \text { points } \leq \text { median; } \\
1 \text { point }>\text { median }\end{array}$ & Included in fruit group \\
\hline Fish & $\begin{array}{l}0 \text { points } \leq \text { median; } \\
1 \text { point }>\text { median }\end{array}$ & $\begin{array}{l}\text { Tertile } 1=0 \text { points; } \\
\text { Tertile } 2=1 \text { point; } \\
\text { Tertile } 3=2 \text { points }\end{array}$ \\
\hline Cereals & $\begin{array}{l}\text { only whole grain } \\
0 \text { points } \leq \text { median; } \\
1 \text { point }>\text { median }\end{array}$ & $\begin{array}{l}\text { Tertile } 1=0 \text { points; } \\
\text { Tertile } 2=1 \text { point; } \\
\text { Tertile } 3=2 \text { points }\end{array}$ \\
\hline Meat & $\begin{array}{c}\text { (Red and processed meat) } \\
0 \text { points } \geq \text { median; } \\
1 \text { point }<\text { median }\end{array}$ & $\begin{array}{l}\text { (All type of meats) } \\
\text { Tertile } 1=2 \text { point; } \\
\text { Tertile } 2=1 \text { point; } \\
\text { Tertile } 3=0 \text { points }\end{array}$ \\
\hline Dairy products & Not included & $\begin{array}{l}\text { (including skimmed) } \\
\text { Tertile } 1=2 \text { point; } \\
\text { Tertile } 2=1 \text { point; } \\
\text { Tertile } 3=0 \text { points }\end{array}$ \\
\hline Mano/Saturated fats ratio & $\begin{array}{l}0 \text { points } \geq \text { median; } \\
1 \text { point }<\text { median }\end{array}$ & Not included \\
\hline Alcohol & Not included & Not included \\
\hline Potatoes & Included in vegetable groups & Not included \\
\hline Olive oil cooking & $\begin{array}{l}\text { Included in mono/saturated } \\
\text { fats ratio group }\end{array}$ & $\begin{array}{l}\text { Tertile } 1=0 \text { points; } \\
\text { Tertile } 2=1 \text { point; } \\
\text { Tertile } 3=2 \text { points }\end{array}$ \\
\hline Poultry & Not included & Included in meat group \\
\hline Score range & $0-9$ points & $0-16$ points \\
\hline Adherence category & $\begin{array}{l}\text { Low }=0-3 \text { points; } \\
\text { Medium }=4-5 \text { points; } \\
\text { High }=\geq 6 \text { points }\end{array}$ & $\begin{array}{l}\text { Low }=0-5 \text { points; } \\
\text { Medium = 6-11 points; } \\
\text { High }=12-16 \text { points }\end{array}$ \\
\hline
\end{tabular}

The aMED is also a version adapted by Fung and colleagues in 2005 [30] and used by Chazti et al. (2013) [7] in different publications. This indicator has eight components (nine originally) and a range from 0 to 8 . For the beneficial components (vegetables, fruits, fish and seafood, nuts, legumes, and whole cereals), women whose consumption 
was below the median (cohort-specific median) were assigned a value of 0 , and women whose consumption was at or above the median were assigned a value of 1 . For the components presumed to be detrimental (red meat, liver, hamburgers, and processed meats), the computation was inversed. For fat intake (the eight-food category), we used the ratio of daily consumption of mono-unsaturated lipids to saturated lipids. The total MD score was categorized to reflect three levels of adherence: $(1) \leq 3$, low; (2) 4-5, medium; and (3) 6-8, high MD quality in each index separately. The main difference between the two scores was that the aMED separated fruits and nuts into two independent groups and did not take into account the intake of dairy products in the indicator. Additionally, it included only whole grains in the cereal component, and white meat was not included in the group of meats and processed meats. Finally, the ratio of mono-unsaturated to saturated fat was included as a fat source (see Table 1).

The Alternate Healthy Eating Index-2010 (AHEI-2010), which is a variation of the AHEI created by Fung et al. in 2005 [30] and has been associated with lower mortality and lower risk of diseases, was created by Chiuve et al. in 2012 [34] and was also used in our study. It is a measure of diet quality based on American dietary guidelines and with modified recommendations from the US Department of Agriculture [27]. This index originally consists of 11 components, one of them being alcohol consumption, and a range from 0 to 110. When it comes to applying this index to our study (pregnant women), an adaptation of the AHEI-2010 was performed eliminating the alcohol component. Due to this modification, the score range changed from 0 to 100 points, as each of the components, 10 in total (instead of 11), contribute with 10 possible points (See Table S1). For intermediate intakes, the proportional part between 0 and 10 was calculated by multiplying the number of daily rations consumed by 10 and then dividing by the criterion for a maximum score for that food group [35]. For example, for zero servings of fruit per day, a score of 0 was assigned; for one serving per day, a score of 2.5 was assigned as four servings per day was considered to be ideal. In this index, as in the case of the aMED, only the whole grain was considered within the group of cereals; the nuts, instead of being included in the fruit component, were included together with the legumes. Regarding meats, the component was composed of red meat and processed meats. Finally, polyunsaturated fats were divided into several items, and sodium consumption was considered. For the transformation of the continuous variable into three degrees of adherence, the quintiles of the scores of the study population were calculated and the three intervals were established: low (42-58 points), medium (59-64 points), and high (65-81 points).

\subsection{Potential Determinants of Adherence to Mediterranean Dietary Patterns}

Information on the following sociodemographic characteristics and lifestyle patterns, which have an established or a potential association with a lower level of adherence to a MD in pregnancy, was collected through questionnaires administered in person during pregnancy: maternal age; parity (0, nulliparous; vs. 1 or more, no nulliparous); gestational diabetes (yes/no); maternal education level (incomplete secondary or less, complete secondary, and university); maternal social class (defined as maternal occupation during pregnancy by using a widely used Spanish adaptation of the international ISCO88 coding system: I-II, managers/technicians; III, skilled; IV-V, semiskilled/unskilled; and unemployed) [36]; maternal body mass index (BMI $\mathrm{kg} / \mathrm{m}^{2}$ ) based on height and prepregnancy self-reported weight $\left(\mathrm{kg} / \mathrm{m}^{2}\right)$ (categorized as normal BMI $<25$, overweight BMI 25-29.99, and obesity BMI $\geq 30$ ), maternal smoking and consumption of alcohol during the first 20 weeks of gestation (yes/no); mother's residential area (urban, residential, and rural). Additionally, questions about physical activity or sedentary lifestyle during the pregnancy period were included in the questionnaire, focused on sedentary activity time (three possible answers: $<1 \mathrm{~h}$ a day, $1-2 \mathrm{~h}$ per day, or $\geq 3 \mathrm{~h}$ per day), sports activity time (three possible answers: no exercise, up to $1 \mathrm{~h}$ per week, or $\geq 2 \mathrm{~h}$ per week), and overall physical activity (self-reported), defined as "sedentary/low active", "moderately active", and "strong active". 


\subsection{Statistical Analysis}

Data analysis was performed using RStudio version 1.2.5001 (RStudio Team (2019), Boston, MA) [37]. The median and interquartile range (IQR) were calculated for the quantitative variables of the study, and relative frequency distribution was estimated for the qualitative variables. The non-parametric Kruskal-Wallis test or Mann-Whitney U test was performed for statistical comparisons between the median aMED, rMED, and AHEI-2010 scores of the study population according to the sociodemographic and lifestyle factors of the population. The Spearman correlation test was used to study the correlation between the two MD indices.

The three indices were modelled as continuous variables through multivariable linear regression as categorical variables and through multivariable logistic regression (low vs. medium-high adherence) analysis to identify factors associated with probability of low MDA ( $\leq 3$ points aMED; $\leq 5$ points $\mathrm{rMED}$ ) and low level of adherence to a healthy diet ( $\leq 58$ points AHEI-2010). A medium and high level of adherence to aMED, rMED, and AHEI-2010 were taken as the reference category. Significance for all the tests carried out was set at $p$-value $<0.05$.

\section{Results}

The distribution of baseline characteristics of the mothers participating in the Spanish NELA cohort at 20 weeks of gestation are in Table 2. The median age of the mothers at the time of recruitment was 33 years with a median weight of $62 \mathrm{~kg}$ and BMI $23.03 \mathrm{~kg} / \mathrm{m}^{2}$. A total of $49.6 \%$ were primiparous and $8.2 \%$ had gestational diabetes. More than a half of the cohort (71.7\%) lived in urban areas; $55.6 \%$ had completed university studies and $18.8 \%$ uncompleted secondary or less education. A total of $16.1 \%$ of the mothers reported to smoke during pregnancy, and $5.7 \%$ reported alcohol consumption. A total of $37.4 \%$ belonged to a high social class, and $20.9 \%$ were unemployed. A total of $57.9 \%$ of the mothers reported that within their leisure time they spent an average of 1 or $2 \mathrm{~h}$ a day doing sedentary activities such as watching television, using a computer, or reading. A total of $56.8 \%$ of mothers did not practice any kind of sport, and within the group that did some sport activity, the majority (60.2\%) reported a sedentary/low active lifestyle.

The median adherence of the cohort corresponded to a score of 4.00 (interquartile range (IQR); 3.00-5.00) and 8.00 (IQR; 6.00-10.00) for the aMED and rMED indices, respectively. Both scores on the 3-level categorical scale (low, medium, and high) would be equivalent to a medium level of MDA. Even though there was a significant correlation between the two indices aMED and rMED (Figure S1), significant differences were observed in the MDA distribution when applying the two indices to the study population (Figure 1$)(p<0.01)$. Specifically, in the case of the aMED index, $43.2 \%$ and $19.1 \%$ of the mothers presented a low and high degree of adherence, respectively, compared to $17.4 \%$ and $8.9 \%$ when the rMED index was applied.

In our study, the median score obtained by applying the AHEI-2010 index was 61 points (IQR; 55.00-65.00) (Table 2), corresponding to a medium level of adherence. However, $37.4 \%$ of the mothers were classified with a low degree of adherence compared to $28.5 \%$ of the mothers who were classified with a high adherence to a healthy diet (Figure 1). 


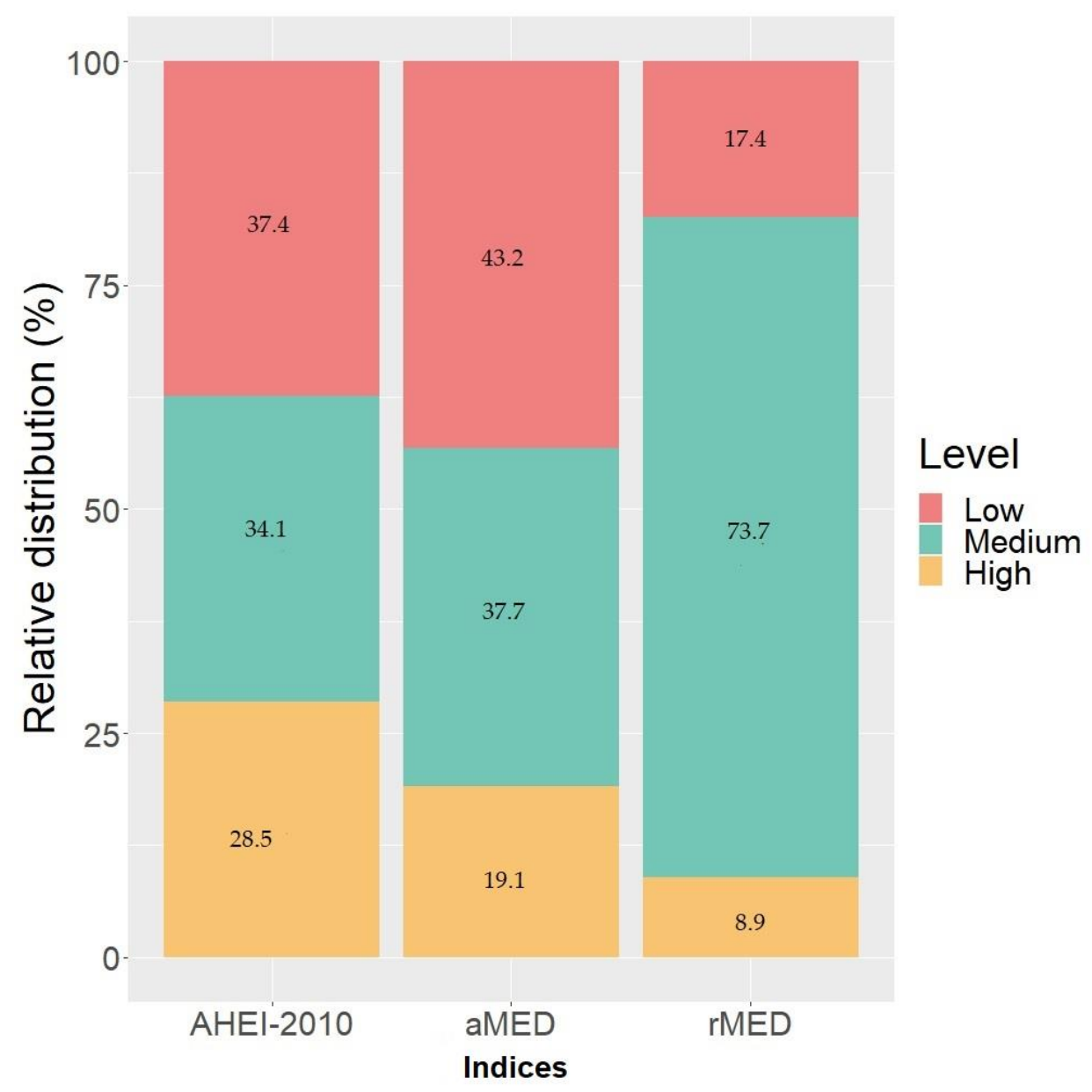

Figure 1. Distribution (\%) of the study population according to the degree of adherence to the Mediterranean diet (the Alternative Mediterranean Diet (aMED) and the Relative Mediterranean Diet (rMED)) and degree of adherence to a healthy diet pattern (AHEI-2010) during pregnancy in the Nutrition in Early Life and Asthma (NELA) cohort.

Table 2. Baseline characteristics of pregnant women at week 20 of pregnancy. NELA birth cohort study $(n=665)$.

\begin{tabular}{|c|c|c|c|c|c|c|}
\hline & $n$ & $\%$ & Median & IQR & Min & Max \\
\hline Maternal age (years) & & & 33.00 & $(30.00-36.00)$ & 18.00 & 45.00 \\
\hline \multicolumn{7}{|l|}{ Anthropometric measures $(n=661)$} \\
\hline Height (m) & & & 1.64 & $(1.60-1.68)$ & 1.47 & 1.82 \\
\hline Weight (kg) & & & 62.00 & $(56.00-70.00)$ & 40.00 & 119.00 \\
\hline Body mass index $\left(\mathrm{kg} / \mathrm{m}^{2}\right)$ & & & 23.03 & $(20.83-25.88)$ & 16.23 & 42.44 \\
\hline Normal weight $(<25)$ & 456 & 69.0 & 21.59 & $(20.25-23.15)$ & 16.23 & 24.98 \\
\hline Overweight (25-29.99) & 143 & 21.6 & 26.71 & $(25.77-28.05)$ & 25.00 & 29.86 \\
\hline Obese $(\geq 30)$ & 62 & 9.4 & 33.89 & $(31.27-37.16)$ & 30.00 & 42.44 \\
\hline Parity, nulliparous & 330 & 49.6 & & & & \\
\hline Gestational diabetes $(n=649)$ & 53 & 8.2 & & & & \\
\hline \multicolumn{7}{|l|}{ Area } \\
\hline Urban area & 477 & 71.7 & & & & \\
\hline Residential & 96 & 14.4 & & & & \\
\hline Rural & 92 & 13.8 & & & & \\
\hline \multicolumn{7}{|l|}{ Maternal education } \\
\hline Incomplete secondary or less & 125 & 18.8 & & & & \\
\hline Complete secondary & 170 & 25.6 & & & & \\
\hline University & 370 & 55.6 & & & & \\
\hline
\end{tabular}


Table 2. Cont.

\begin{tabular}{|c|c|c|c|c|c|c|}
\hline & $n$ & $\%$ & Median & IQR & Min & Max \\
\hline Maternal smoking & 107 & 16.1 & & & & \\
\hline Maternal alcohol consumption & 38 & 5.7 & & & & \\
\hline \multicolumn{7}{|l|}{ Maternal social class } \\
\hline $\mathrm{I}-\mathrm{II}$ & 249 & 37.4 & & & & \\
\hline III & 146 & 22.0 & & & & \\
\hline IV-V & 131 & 19.7 & & & & \\
\hline Unemployed & 139 & 20.9 & & & & \\
\hline \multicolumn{7}{|l|}{ Diet index ( 20 weeks) } \\
\hline aMED & & & 4.00 & $(3.00-5.00)$ & 0.00 & 8.00 \\
\hline rMED & & & 8.00 & $(6.00-10.00)$ & 2.00 & 15.00 \\
\hline AHEI-2010 & & & 61.00 & $(55.00-65.00)$ & 42.00 & 81.00 \\
\hline Use of probiotics $(n=622)$ & 108 & 17.4 & & & & \\
\hline \multicolumn{7}{|c|}{ Sedentary activity time (hours/day) $(n=663)$} \\
\hline$<1 \mathrm{~h}$ per day & 76 & 11.5 & & & & \\
\hline $1-2 \mathrm{~h}$ per day & 384 & 57.9 & & & & \\
\hline$\geq 3 \mathrm{~h}$ per day & 203 & 30.6 & & & & \\
\hline \multicolumn{7}{|l|}{ Sports activity time (hours/week) } \\
\hline Not exercise or sports & 378 & 56.8 & & & & \\
\hline up to $1 \mathrm{~h}$ per week & 88 & 13.2 & & & & \\
\hline$\geq 2 \mathrm{~h}$ per week & 199 & 29.9 & & & & \\
\hline \multicolumn{7}{|l|}{ Physical activity (self-report) } \\
\hline Sedentary/low active & 400 & 60.2 & & & & \\
\hline Moderately active & 235 & 35.3 & & & & \\
\hline Strong active & 30 & 4.5 & & & & \\
\hline
\end{tabular}

IQR: interquartile range.

Table 3 presents the analysis of the association between sociodemographic and lifestyle factors and the two MDA scores applying (aMED and rMED). The same analysis was carried out applying the AHEI-2010 index (Table 4). When the aMED index was applied, it was observed that the mothers who had an older age, were non-smokers, as well as having a higher educational level and higher social class, and those who practice sports activities $\geq 2 \mathrm{~h}$ per week had a higher level of adherence to $\mathrm{MD}(p<0.01)$. In the case of the rMED index, older non-smoking mothers with a higher educational level and higher social class, who practice sports activities $\geq 2 \mathrm{~h}$ per week, and/or have gestational diabetes had a higher MDA $(p<0.05)$.

Table 3. Sociodemographic and lifestyle characteristics of women at week 20 of pregnancy according to the Alternative Mediterranean Diet and Relative Mediterranean Diet indexes score distribution. NELA birth cohort study $(n=665)$.

\begin{tabular}{|c|c|c|c|c|c|c|c|c|}
\hline & \multirow[b]{2}{*}{$n$} & \multirow[b]{2}{*}{$\%$} & \multicolumn{3}{|c|}{$\begin{array}{l}\text { Alternative Mediterranean Diet } \\
\text { (aMED) Index Score (Points) }\end{array}$} & \multicolumn{3}{|c|}{$\begin{array}{l}\text { Relative Mediterranean Diet } \\
\text { (rMED) Index Score (Points) }\end{array}$} \\
\hline & & & Median & $I Q R$ & $p$ & Median & $I Q R$ & $p$ \\
\hline Maternal age (years) & & & & & $<0.0001$ & & & $<0.0001$ \\
\hline$\geq 40$ & 46 & 6.92 & 4.50 & $(3.00-5.75)$ & & 10.00 & $(7.25-11.00)$ & \\
\hline $35-39$ & 191 & 28.72 & 4.00 & $(3.00-5.50)$ & & 8.00 & $(7.00-10.00)$ & \\
\hline $30-34$ & 288 & 43.31 & 4.00 & $(3.00-5.00)$ & & 8.00 & $(6.00-10.00)$ & \\
\hline $25-29$ & 109 & 16.39 & 3.00 & $(2.00-5.00)$ & & 7.00 & $(5.00-9.00)$ & \\
\hline$<25$ & 31 & 4.66 & 2.00 & $(1.00-4.00)$ & & 5.00 & $(4.00-8.00)$ & \\
\hline Body mass index $\left(\mathrm{kg} / \mathrm{m}^{2}\right)(n=661)$ & & & & & 0.30 & & & 0.73 \\
\hline Normal weight $(<25)$ & 456 & 69.0 & 4.00 & $(3.00-5.00)$ & & 8.00 & $(6.00-10.00)$ & \\
\hline Overweight (25-29.99) & 143 & 21.6 & 4.00 & $(2.50-5.00)$ & & 8.00 & $(6.00-10.00)$ & \\
\hline Obese $(\geq 30)$ & 62 & 9.4 & 3.00 & $(2.25-5.00)$ & & 8.00 & $(5.25-10.00)$ & \\
\hline $\begin{array}{c}\text { Parity (number of previous } \\
\text { deliveries) }\end{array}$ & & & & & 0.06 & & & 0.66 \\
\hline Nulliparous & 330 & 49.62 & 4.00 & $(3.00-5.00)$ & & 8.00 & $(6.00-10.00)$ & \\
\hline One or more previous deliveries & 335 & 50.38 & 4.00 & $(3.00-5.00)$ & & 8.00 & $(6.00-10.00)$ & \\
\hline
\end{tabular}


Table 3. Cont.

\begin{tabular}{|c|c|c|c|c|c|c|c|c|}
\hline & \multirow[b]{2}{*}{$n$} & \multirow[b]{2}{*}{$\%$} & \multicolumn{3}{|c|}{$\begin{array}{l}\text { Alternative Mediterranean Diet } \\
\text { (aMED) Index Score (Points) }\end{array}$} & \multicolumn{3}{|c|}{$\begin{array}{l}\text { Relative Mediterranean Diet } \\
\text { (rMED) Index Score (Points) }\end{array}$} \\
\hline & & & Median & $I Q R$ & $p$ & Median & $I Q R$ & $p$ \\
\hline Gestational diabetes $(n=649)$ & & & & & 0.25 & & & 0.028 \\
\hline No & 596 & 91.83 & 4.00 & $(3.00-5.00)$ & & 8.00 & $(6.00-10.00)$ & \\
\hline Yes & 53 & 8.17 & 4.00 & $(3.00-6.00)$ & & 9.00 & $(7.00-11.00)$ & \\
\hline Area & & & & & 0.21 & & & 0.50 \\
\hline Urban area & 477 & 71.73 & 4.00 & $(3.00-5.00)$ & & 8.00 & $(6.00-10.00)$ & \\
\hline Residential area & 96 & 14.44 & 4.00 & $(3.00-5.00)$ & & 8.00 & $(7.00-10.00)$ & \\
\hline Rural & 92 & 13.83 & 4.00 & $(2.75-5.00)$ & & 8.00 & $(6.75-10.00)$ & \\
\hline Maternal education & & & & & $<0.0001$ & & & $<0.0001$ \\
\hline Incomplete secondary or less & 125 & 18.80 & 3.00 & $(2.00-4.00)$ & & 7.00 & $(5.00-9.00)$ & \\
\hline Complete secondary and superior & 170 & 25.56 & 4.00 & $(2.25-5.00)$ & & 7.50 & $(6.00-9.00)$ & \\
\hline University & 370 & 55.64 & 4.00 & $(3.00-5.00)$ & & 8.50 & $(7.00-10.00)$ & \\
\hline Maternal social class & & & & & $<0.0001$ & & & $<0.0001$ \\
\hline I-II & 239 & 35.94 & 4.00 & $(3.00-6.00)$ & & 8.00 & $(7.00-10.00)$ & \\
\hline III & 150 & 22.56 & 4.00 & $(3.00-5.00)$ & & 8.00 & $(6.00-10.00)$ & \\
\hline IV-V & 127 & 19.10 & 3.00 & $(2.00-5.00)$ & & 8.00 & $(6.00-9.00)$ & \\
\hline Unemployed & 149 & 22.41 & 3.00 & $(2.00-5.00)$ & & 7.00 & $(5.00-9.00)$ & \\
\hline Maternal Smoking & & & & & 0.009 & & & 0.001 \\
\hline No & 558 & 83.91 & 4.00 & $(3.00-5.00)$ & & 8.00 & $(6.00-10.00)$ & \\
\hline Yes & 107 & 16.09 & 3.00 & $(2.00-5.00)$ & & 7.00 & $(5.00-9.00)$ & \\
\hline Maternal alcohol consumption & & & & & 0.20 & & & 0.17 \\
\hline No & 627 & 94.29 & 4.00 & $(3.00-5.00)$ & & 8.00 & $(6.00-10.00)$ & \\
\hline Yes & 38 & 5.71 & 3.50 & $(2.00-4.75)$ & & 7.00 & $(6.00-9.00)$ & \\
\hline Use of probiotics $(n=622)$ & & & & & 0.16 & & & 0.10 \\
\hline No & 514 & 82.64 & 4.00 & $(3.00-5.00)$ & & 8.00 & $(6.00-10.00)$ & \\
\hline Yes & 108 & 17.36 & 4.00 & $(3.00-5.00)$ & & 8.00 & $(7.00-10.25)$ & \\
\hline $\begin{array}{l}\text { Sedentary activity time (hours) } \\
\qquad(n=663)\end{array}$ & & & & & 0.31 & & & 0.16 \\
\hline$<1 \mathrm{~h}$ per day & 76 & 11.5 & 4.00 & $(3.00-5.00)$ & & 8.00 & $(6.00-10.00)$ & \\
\hline $1-2 \mathrm{~h}$ per day & 384 & 57.9 & 4.00 & $(3.00-5.00)$ & & 8.00 & $(6.75-10.00)$ & \\
\hline$\geq 3 \mathrm{~h}$ per day & 203 & 30.6 & 4.00 & $(2.00-5.00)$ & & 8.00 & $(6.00-10.00)$ & \\
\hline Sports activity time (hours) & & & & & $<0.0001$ & & & $<0.0001$ \\
\hline No exercise or sports & 378 & 57.1 & 3.00 & $(2.00-5.00)$ & & 8.00 & $(6.00-9.00)$ & \\
\hline Up to $1 \mathrm{~h}$ per week & 88 & 13.3 & 4.00 & $(2.00-5.00)$ & & 8.00 & $(6.00-10.00)$ & \\
\hline$\geq 2 \mathrm{~h}$ per week & 199 & 30.1 & 5.00 & $(3.00-6.00)$ & & 9.00 & $(7.00-11.00)$ & \\
\hline Physical activity (self-report) & & & & & $<0.0001$ & & & 0.05 \\
\hline Sedentary/low active & 400 & 60.4 & 4.00 & $(2.00-5.00)$ & & 8.00 & $(6.00-10.00)$ & \\
\hline Moderately active & 235 & 35.5 & 4.00 & $(3.00-5.00)$ & & 8.00 & $(6.00-10.00)$ & \\
\hline Strong active & 30 & 4.5 & 5.00 & $(4.00-6.00)$ & & 8.50 & $(6.00-10.75)$ & \\
\hline
\end{tabular}

Non-smoking mothers with an older age, a higher educational level and a higher social class, a strong active (self-reported) lifestyle, and / or those practice sports activities $\geq 2 \mathrm{~h}$ per week had a higher AHEI-2010 diet pattern $(p<0.05)$ (Table 4$)$. No association with adherence was observed for the remaining variables, including BMI and sedentary activity.

For aMED and rMED indices, older age and practicing regular physical activity $\geq 2 \mathrm{~h}$ per week were positively associated with MDA scores (see Table 5). The higher the number of previous deliveries, the lower the aMED index score ( $\beta$ : -0.29$)$; (95\% IC: $-0.49 ;-0.09$; $p<0.01)$. Only in the rMED index, a university educational level of the mother was associated with a better score in rMED index ( $\beta$ : 0.85$)$; (95\% IC: $0.22 ; 1.49 ; p<0.01)$. In both indices, a younger age was significantly associated with a higher risk of low MDA. (aMED; OR: 0.92; 95\% CI: 0.88-0.96; $p<0.01$; rMED; OR: 0.88; 95\% CI: 0.83-0.93, $p<0.01$ ). The number of previous deliveries was directly associated with a greater risk of a low MDA for each previous child (aMED; OR: 1.40; 95\% CI: 1.08-1.82; $p<0.05$; rMED; OR: 1.38 ; 95\% CI: $1.00-1.89, p<0.05)$. Only for the aMED index was it observed that university education 
was significantly associated with a lower risk of low MDA (OR: 0.48; 95\% CI: $0.28-0.83$; $p<0.01)$. Regarding the mother's sports activity and MDA, in the aMED index a lower risk of low adherence was obtained as the weekly hours of sports activity were $\geq 2 \mathrm{~h}$ per week (OR: $0.54,95 \%$ CI: $0.36-0.81, p<0.01$ ). It was observed that living in residential and rural areas decreased the risk of a low MDA but only in the rMED index.

Table 4. Sociodemographic and lifestyle characteristics of women at week 20 of pregnancy according to the Alternative Healthy Eating Index 2010 score distribution. NELA birth cohort study $(n=665)$.

\begin{tabular}{|c|c|c|c|}
\hline & \multicolumn{3}{|c|}{ Alternative Healthy Eating Index Score (AHEI-2010) } \\
\hline & Median & IQR & $p$ \\
\hline Maternal age (years) & & & $<0.0001$ \\
\hline$\geq 40$ & 63.00 & $(59.00-66.75)$ & \\
\hline $35-39$ & 62.00 & $(57.00-66.00)$ & \\
\hline $30-34$ & 61.00 & $(56.00-66.00)$ & \\
\hline $25-29$ & 58.00 & $(55.00-63.00)$ & \\
\hline$<25$ & 55.00 & $(52.50-62.50)$ & \\
\hline Body mass index $\left(\mathrm{kg} / \mathrm{m}^{2}\right)(n=661)$ & & & 1.00 \\
\hline Normal weight $(<25)$ & 61.00 & $(55.00-66.00)$ & \\
\hline Overweight (25-29.99) & 61.00 & $(56.00-65.00)$ & \\
\hline Obese $(\geq 30)$ & 60.00 & $(55.00-65.00)$ & \\
\hline Parity (number of previous deliveries) & & & 0.05 \\
\hline Nulliparous & 60.00 & $(55.00-65.00)$ & \\
\hline One or more previous deliveries & 61.00 & $(56.00-66.00)$ & \\
\hline Gestational diabetes $(n=649)$ & & & 0.66 \\
\hline No & 61.00 & $(56.00-66.00)$ & \\
\hline Yes & 60.00 & $(55.00-64.00)$ & \\
\hline Area & & & 0.23 \\
\hline Urban area & 60.00 & $(55.00-65.00)$ & \\
\hline Residential area & 62.00 & $(57.75-65.00)$ & \\
\hline Rural & 62.00 & $(56.00-66.00)$ & \\
\hline Maternal education & & & $<0.0001$ \\
\hline Incomplete secondary or less & 58.00 & $(54.00-64.00)$ & \\
\hline Complete secondary and superior & 59.50 & $(55.00-64.00)$ & \\
\hline University & 62.00 & $(57.00-66.00)$ & \\
\hline Maternal social class & & & 0.002 \\
\hline I-II & 62.00 & $(58.00-66.00)$ & \\
\hline III & 60.50 & $(55.25-65.00)$ & \\
\hline IV-V & 59.00 & $(54.00-64.00)$ & \\
\hline Unemployed & 60.00 & $(55.00-65.00)$ & \\
\hline Maternal Smoking & & & $<0.0001$ \\
\hline No & 61.00 & $(56.00-66.00)$ & \\
\hline Yes & 58.00 & $(54.00-63.00)$ & \\
\hline Maternal alcohol consumption & & & 0.08 \\
\hline No & 61.00 & $(56.00-65.50)$ & \\
\hline Yes & 59.50 & $(53.25-63.75)$ & \\
\hline Use of probiotics $(n=622)$ & & & 0.51 \\
\hline No & 61.00 & $(56.00-66.00)$ & \\
\hline Yes & 60.00 & $(55.00-64.25)$ & \\
\hline Sedentary activity time (hours) $(n=663)$ & & & 0.65 \\
\hline$<1 \mathrm{~h}$ per day & 62.00 & $(55.75-66.00)$ & \\
\hline $1-2 \mathrm{~h}$ per day & 61.00 & $(56.00-65.00)$ & \\
\hline$\geq 3 \mathrm{~h}$ per day & 61.00 & $(55.00-65.00)$ & \\
\hline Sports activity time (hours) & & & 0.014 \\
\hline No exercise or sports & 60.00 & $(55.00-65.00)$ & \\
\hline Up to $1 \mathrm{~h}$ per week & 61.00 & $(58.00-66.00)$ & \\
\hline$\geq 2 \mathrm{~h}$ per week & 62.00 & $(56.00-66.00)$ & \\
\hline Physical activity (self-report) & & & 0.019 \\
\hline Sedentary/low active & 60.50 & $(56.00-65.00)$ & \\
\hline Moderately active & 61.00 & $(55.00-66.00)$ & \\
\hline Strong active & 64.00 & $(61.25-67.00)$ & \\
\hline
\end{tabular}

Bold values mean "statistical significance" ( $p$-value $<0.05)$. Numbers were expressed as median and interquartile range (IQR) for the quantitative variables. Statistical caparisons using non-parametric Mann-Whitney U test or Kruskal-Wallis test. 


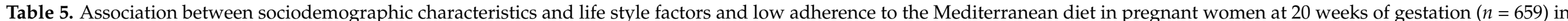
the NELA cohort study.

\begin{tabular}{|c|c|c|c|c|c|c|c|c|c|c|c|c|}
\hline & \multicolumn{6}{|c|}{ aMED } & \multicolumn{6}{|c|}{ rMED } \\
\hline & $\beta^{+}$ & $(95 \% \mathrm{CI})$ & & OR $\ddagger$ & $(95 \% \mathrm{CI})$ & & $\beta^{+}$ & $(95 \% \mathrm{CI})$ & & OR $\ddagger$ & $(95 \% \mathrm{CI})$ & \\
\hline Maternal age (years) ${ }^{\S}$ & 0.09 & $(0.06 ; 0.12)$ & $* *$ & 0.92 & $(0.88-0.96)$ & $* *$ & 0.14 & $(0.09 ; 0.19)$ & $* *$ & 0.88 & $(0.83-0.93)$ & ** \\
\hline \multicolumn{13}{|l|}{ Body mass index $\left(\mathrm{kg} / \mathrm{m}^{2}\right)$} \\
\hline Normal weight $(<24.99)$ & Ref & & & Ref & & & Ref & & & Ref & & \\
\hline Overweight (25-29.9) & -0.08 & $(-0.41 ; 0.25)$ & & 1.07 & $(0.70-1.61)$ & & 0.08 & $(-0.39 ; 0.55)$ & & 0.83 & $(0.47-1.44)$ & \\
\hline Obese $(\geq 30)$ & 0.10 & $(-0.36 ; 0.56)$ & & 1.07 & $(0.60-1.93)$ & & 0.15 & $(-0.52 ; 0.82)$ & & 1.28 & $(0.64-2.50)$ & \\
\hline Parity (number of previous deliveries) $\S$ & -0.29 & $(-0.49 ;-0.09)$ & ** & 1.40 & $(1.08-1.82)$ & * & -0.20 & $(-0.48 ; 0.09)$ & & 1.38 & $(1.00-1.89)$ & * \\
\hline \multicolumn{13}{|l|}{ Area } \\
\hline Urban area & Ref & & & Ref & & & Ref & & & Ref & & \\
\hline Rural & -0.16 & $(-0.54 ; 0.22)$ & & 1.08 & $(0.67-1.76)$ & & 0.41 & $(-0.14 ; 0.96)$ & & 0.41 & $(0.19-0.80)$ & * \\
\hline \multicolumn{13}{|l|}{ Maternal education } \\
\hline Incomplete secondary or less & Ref & & & Ref & & & Ref & & & Ref & & \\
\hline Complete secondary and superior & 0.21 & $(-0.21 ; 0.62)$ & & 0.67 & $(0.40-1.13)$ & & 0.10 & $(-0.50 ; 0.70)$ & & 0.93 & $(0.50-1.73)$ & \\
\hline University & 0.37 & $(-0.08 ; 0.81)$ & & 0.48 & $(0.28-0.83)$ & ** & 0.85 & $(0.22 ; 1.49)$ & ** & 0.80 & $(0.40-1.59)$ & \\
\hline \multicolumn{13}{|l|}{ Maternal social class } \\
\hline I-II & Ref & & & Ref & & & Ref & & & Ref & & \\
\hline III & -0.14 & $(-0.53 ; 0.24)$ & & 1.01 & $(0.61-1.64)$ & & 0.06 & $(-0.49 ; 0.62)$ & & 1.26 & $(0.62-2.52)$ & \\
\hline IV-V & -0.24 & $(-0.69 ; 0.20)$ & & 1.09 & $(0.62-1.92)$ & & 0.02 & $(-0.63 ; 0.66)$ & & 1.19 & $(0.55-2.51)$ & \\
\hline Unemployed & -0.08 & $(-0.51 ; 0.35)$ & & 1.08 & $(0.63-1.86)$ & & -0.12 & $(-0.74 ; 0.50)$ & & 1.30 & $(0.63-2.68)$ & \\
\hline Maternal Smoking, yes & -0.02 & $(-0.39 ; 0.36)$ & & 0.94 & $(0.59-1.51)$ & & -0.17 & $(-0.71 ; 0.36)$ & & 1.11 & $(0.63-1.92)$ & \\
\hline \multicolumn{13}{|l|}{ Sedentary activity time (hours) } \\
\hline$<1$ hour per day & Ref & & & & & & Ref & & & Ref & & \\
\hline $1-2$ hours per day & -0.17 & $(-0.60 ; 0.26)$ & & 1.30 & $(0.76-2.28)$ & & 0.05 & $(-0.57 ; 0.67)$ & & 0.73 & $(0.36-1.53)$ & \\
\hline$\geq 3$ hours per day & -0.28 & $(-0.75 ; 0.19)$ & & 1.35 & $(0.74-2.47)$ & & -0.19 & $(-0.86 ; 0.49)$ & & 1.42 & $(0.68-3.11)$ & \\
\hline \multicolumn{13}{|l|}{ Sports activity time (hours) } \\
\hline Not exercise or sports & Ref & & & Ref & & & Ref & & & Ref & & \\
\hline up to 1 hour per week & 0.08 & $(-0.32 ; 0.49)$ & & 0.69 & $(0.41-1.14)$ & & -0.01 & $(-0.59 ; 0.57)$ & & 1.36 & $(0.72-2.49)$ & \\
\hline$\geq 2$ hour per week & 0.56 & $(0.25 ; 0.87)$ & ** & 0.54 & $(0.36-0.81)$ & $* *$ & 0.82 & $(0.37 ; 1.27)$ & ** & 0.77 & $(0.43-1.35)$ & \\
\hline \multicolumn{13}{|l|}{ Physical activity (self-report) } \\
\hline Sedentary/ low active & Ref & & & Ref & & & Ref & & & Ref & & \\
\hline Moderately active & 0.23 & $(-0.05 ; 0.52)$ & & 0.71 & $(0.49-1.01)$ & & 0.09 & $(-0.32 ; 0.50)$ & & 0.89 & $(0.54-1.44)$ & \\
\hline Strong active & 0.90 & $(0.25 ; 1.56)$ & ** & 0.45 & $(0.17-1.10)$ & & 0.10 & $(-0.85 ; 1.05)$ & & 0.59 & $(0.13-1.95)$ & \\
\hline
\end{tabular}

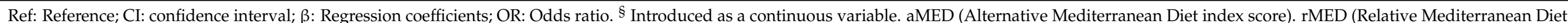

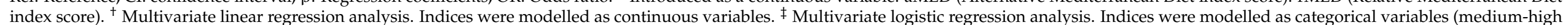

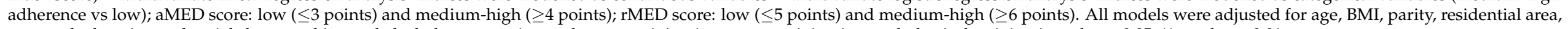
maternal education and social class, smoking and alcohol consumption, sedentary activity time, sport activity time and physical activity. ${ }^{*} p$-value $<0.05$; ${ }^{* *} p$-value $<0.01$. 
Regarding the AHEI-2010 (Table 6), a younger age (OR: 0.92; 95\% CI: 0.88-0.96, $p<0.01$ ) and smoking (OR: 1.70, 95\% CI: 1.07-2.70, $p<0.05)$ were associated with a higher risk of a low AHEI-2010 dietary pattern. Regarding sport activity, up to $1 \mathrm{~h}$ per week of sports activity (OR: 0.56 ; $95 \%$ CI: $0.32-0.96, p<0.05)$ decreases the probability of presenting a low AHEI-2010 dietary pattern.

Table 6. Association between sociodemographic characteristics and lifestyle factors and low adherence to a healthy diet pattern. Alternative Healthy Eating Index (AHEI-2010) in pregnant women at 20 weeks gestation $(n=659)$ in the NELA cohort study.

\begin{tabular}{|c|c|c|c|c|c|c|}
\hline & $\beta^{+}$ & $(95 \% \mathrm{CI})$ & & OR $\ddagger$ & $(95 \% \mathrm{CI})$ & \\
\hline Maternal age (years) $\S$ & 0.31 & $(0.18 ; 0.44)$ & $* *$ & 0.92 & $(0.88-0.96)$ & ** \\
\hline \multicolumn{7}{|l|}{ Body mass index $\left(\mathrm{kg} / \mathrm{m}^{2}\right)$} \\
\hline Normal weight $(<24.99)$ & Ref & & & Ref & & \\
\hline Overweight (25-29.9) & 0.43 & $(-0.88 ; 1.74)$ & & 0.90 & $(0.59-1.37)$ & \\
\hline Obese $(\geq 30)$ & 0.82 & $(-1.04 ; 2.67)$ & & 0.82 & $(0.44-1.50)$ & \\
\hline Parity (number of previous deliveries) $\S$ & -0.24 & $(-1.04 ; 0.55)$ & & 1.01 & $(0.78-1.30)$ & \\
\hline \multicolumn{7}{|l|}{ Area } \\
\hline Urban area & Ref & & & Ref & & \\
\hline Residential area & 0.77 & $(-0.76 ; 2.30)$ & & 0.78 & $(0.46-1.29)$ & \\
\hline Rural & 0.83 & $(-0.70 ; 2.35)$ & & 0.67 & $(0.40-1.10)$ & \\
\hline \multicolumn{7}{|l|}{ Maternal education } \\
\hline Incomplete secondary or less & Ref & & & Ref & & \\
\hline Complete secondary and superior & 1.10 & $(-1.76 ; 1.57)$ & & 0.83 & $(0.49-1.40)$ & \\
\hline University & 0.75 & $(-1.02 ; 2.51)$ & & 0.70 & $(0.40-1.23)$ & \\
\hline \multicolumn{7}{|l|}{ Maternal social class } \\
\hline I-II & Ref & & & Ref & & \\
\hline III & -0.49 & $(-2.03 ; 1.05)$ & & 1.54 & $(0.93-2.54)$ & \\
\hline IV-V & -1.23 & $(-3.02 ; 0.55)$ & & 1.68 & $(0.95-3.00)$ & \\
\hline Unemployed & -0.17 & $(-1.89 ; 1.56)$ & & 1.11 & $(0.62-1.95)$ & \\
\hline Maternal Smoking, yes & -1.26 & $(-2.74 ; 0.23)$ & & 1.70 & $(1.07-2.70)$ & * \\
\hline Maternal alcohol consumption, yes & -1.49 & $(-3.75 ; 0.77)$ & & 1.34 & $(0.65-2.76)$ & \\
\hline \multicolumn{7}{|l|}{ Sedentary activity time (hours) } \\
\hline$<1 \mathrm{~h}$ per day & Ref & & & Ref & & \\
\hline $1-2 \mathrm{~h}$ per day & 0.10 & $(-1.61 ; 1.82)$ & & 0.82 & $(0.43-1.56)$ & \\
\hline$\geq 3 \mathrm{~h}$ per day & 0.15 & $(-1.74 ; 2.03)$ & & 1.16 & $(0.63-2.16)$ & \\
\hline \multicolumn{7}{|l|}{ Sports activity time (hours) } \\
\hline Not exercise or sports & Ref & & & Ref & & \\
\hline up to $1 \mathrm{~h}$ per week & 1.36 & $(-0.26 ; 2.97)$ & & 0.56 & $(0.32-0.96)$ & * \\
\hline$\geq 2 \mathrm{~h}$ per week & 0.80 & $(-0.45 ; 2.05)$ & & 0.72 & $(0.48-1.08)$ & \\
\hline \multicolumn{7}{|l|}{ Physical activity (self-report) } \\
\hline Sedentary/low active & Ref & & & Ref & & \\
\hline Moderately active & -0.19 & $(-1.33 ; 0.95)$ & & 1.54 & $(1.07-2.23)$ & * \\
\hline Strong active & 2.64 & $(0.02 ; 5.27)$ & * & 0.35 & $(0.10-1.00)$ & \\
\hline
\end{tabular}

Ref: Reference; CI: confidence interval; $\beta$ : Regression coefficients; OR: Odds ratio. AHEI-2010 (Alternative Healthy Index score). $\S$ Introduced as a continuous variable. + Multivariate linear regression analysis. Indices were modelled as continuous variable. $\ddagger$ Multivariate logistic regression analysis. Indices modelled as categorical variable (medium-high vs low adherence); AHEI-2010 score: low ( $\leq 58$ points) and medium-high ( $>58$ points). Both models were adjusted for age, BMI, parity, residential area, maternal education and social class, smoking and alcohol consumption, sedentary activity time, sport activity time and physical activity. ${ }^{*} p$-value $<0.05 ;{ }^{* *} p$-value $<0.01$.

\section{Discussion}

In the current prospective cohort study, three different dietary indices based on the data from an FFQ collected at 20 weeks of pregnancy were calculated. In relation to the sociodemographic and lifestyle factors, we found a markedly protective effect on age for the three dietary indices. The older they are, the higher the chance of a good MDA or a diet associated with a lower risk of cardiovascular disease. Additionally, the educational level of the mother and fewer previous deliveries were other variables with a protective effect for MDA, decreasing the probability of poor adherence. These protective markers coincide with those observed by other authors $[23,38]$. In other studies, the authors observed that 
a healthy dietary pattern in pregnant women was positively associated with older age, a higher educational level, a higher social class, and greater physical activity [23,39-42]. Other authors also observed a negative association between the number of previous deliveries and a healthy diet pattern [39,41,42]. In relation to smoking and BMI, contradictory results have been reported. In certain studies, smoke and BMI have been negatively associated with a healthy diet pattern [41,42], while in others overweight/obesity was positively associated [39].

Despite the high degree of correlation that has been observed between the two MD indices (aMED and rMED), statistically significant differences have been observed in the distributions of three groups into which the population can be divided according to their degree of adherence. In general, while previous studies have applied a single index of adherence to study the MD in pregnant women, this is the first study, to our knowledge, in which two different scores have been applied to characterize the MDA in pregnant women along with a third index which represents a healthy diet pattern.

The level of adherence to the MD (aMED) as well as that of the healthy-style diet of pregnant women belonging to our study was in line with that observed in the study carried out by Lange et al. in 2010 [35], whose study population was characterized by presenting a medium level of adherence for both indices (4.6 points in the aMED index and 61 points in the AHEI-2010 index). Our results are also very similar in reference to the percentage of mothers who present a low and high MDA index (using the aMED index) to the results observed by Chatzi et al. in 2012 [43] (42\% and 15\%, respectively) for a population residing in the Mediterranean area. However, in another study also carried out by Chatzi et al. in 2013 [7], a lower proportion of mothers with a high level of adherence (approx. 7.5\% in the population of Valencia) (applying the aMED index) were found, compared to our population (19.1\%) despite the proximity of both areas (southern of Spain). On the other hand, we consider it necessary to highlight the trend observed in recent years towards a worsening of the adherence to the MD by the Spanish adult population, who are classified with a low adherence and adopting a less healthy diet (typical of Western countries) [38,44]. It would be interesting to carry out studies to ascertain if this trend is observed in Spanish pregnant women, since it is a period in which mothers tend to be more careful in the choice of foods they eat and avoid certain habits that could be harmful to their health and the health of their offspring.

The differences observed in the distributions of the population according to the MDA between both indices may be due to two issues: (a) the differences in the determination of the foods that make up the single group and (b) the different criteria that exist when trying to differentiate the food groups that conform to the MD pattern, such as olive oil, red meat, dairy products, and cereals. In the case of olive oil, one of the main foods that define MD, the aMED index does not take this ingredient into account as an individual group, while the rMED index does, considering it positive. As a result of these differences, in other cohorts formed in the United Kingdom [45] or the United States [35], where MD is also studied using the aMED index, a lower percentage of low adherence (39.1\%) and a higher average MDA value (4.6 points) has been observed, respectively, compared to our cohort, despite being geographic areas where following an MD is not the most common.

It must be considered that our population group has nutritional requirements different from that of a normal adult. Pregnant women suffer certain alterations during the first months of pregnancy that modify the dietary pattern. Moreover, certain foods are also eliminated from the diet, or their intake is reduced because they are not recommended, such as the consumption of fish with high mercury content, while others are encouraged, such as dairy products as a source of calcium. Regarding the last group, dairy products, there is no consensus when it comes to applying the indices or modifying them for pregnant women. Some studies include dairy as a positive food group [7,33,45], while others apply the rMED index without modifications, considering its consumption as negative due to the high fat content and because they do not differentiate between whole and skimmed dairy products, as in our case following the recommendations [6,31,46]. 
Due to the importance of following a good dietary pattern during pregnancy, it is considered necessary to carry out effective interventions in primary care to promote MDA. Ongoing individual nutritional counseling has been shown to improve nutrition, increasing the intake of dietary fiber, fruits, and vegetables, and reducing the intake of saturated fat [47]. As possible limitations of our study, we must cite the observational nature of the study, with dietary information recorded retrospectively (diet during the first 20 weeks of pregnancy). This may involve some memory bias, possibly reinforced by the social desirability of avoiding the recording of a large intake of unhealthy foods. Such bias would mainly affect mothers with worse eating habits, reducing the variability of the sample and the probability of obtaining significant associations. As possible advantages of our study, the following should be noted: (i) the large sample size and the study population selected from healthy pregnant women in the reference area; thus, the results could be more easily extrapolated to a wider population; (ii) the use of a previously validated FFQ among pregnant women in Spain which may reduce the presence of bias [26]; (iii) the compilation of all the information obtained in the different questionnaires was carried out by trained interviewers; and (iv) the results have been presented for three indices, which allow a better comparability with other studies that use only one index.

\section{Conclusions}

As a general conclusion, in this study pregnant women with a younger age, previous deliveries, low educational level, and who practice unhealthy lifestyles, such as lack of physical activity, are associated with a higher risk of low adherence to the Mediterranean diet (aMED and rMED) and a healthy dietary pattern (AHEI-2010). This fact should be taken into account to design successful educational interventions in the future because, as mentioned above, a healthy diet also has a protective effect on the health of the offspring. The pre-pregnancy and pregnancy periods are an ideal time window to introduce some stimulus that helps to modify dietary and lifestyle habits in a positive way since there is also a very large motivational factor.

Supplementary Materials: The following are available online at https:/ /www.mdpi.com/article/10 $.3390 /$ nu13041248/s1, Figure S1: Correlation study between the three indices used to evaluate the pattern of adherence to the Mediterranean diet (aMED and rMED) and adherence to a healthy diet pattern (AHEI-2010) in the NELA cohort. Table S1: The AHEI-2010 scoring method and mean scores at baseline among pregnant women in the NELA cohort Study.

Author Contributions: C.M.-G., M.S.-P. and G.Y.-G. conceived the study; E.M. and L.G.-M. conceived and supervised the project; E.M., L.G.-M. and C.M.G. recruited the participants; C.M.-G., C.S.-M., M.S.-P., P.P.-E. and J.V. analyzed food frequency questionnaires; C.S.-M., E.M. and C.M.-G. contributed to the statistical analysis; C.M.-G., G-Y.-G., E.M. and J.V. contributed to the discussion of results; and C.S.-M. and C.M.-G. wrote the paper. All authors have read and agreed to the published version of the manuscript.

Funding: This research was supported by grants from Instituto de Salud Carlos III, Spanish Ministry of Science, Innovation and Universities, and Fondos FEDER (grant numbers CP14/00046, PIE15/00051, PI16/00422 and ARADyAL network RD160006, PID2019-106693RB-100/AEI/10.13039/ 501100011033). C.S.-M. was funded by a predoctoral fellowship (FPU MECD 15/05809) awarded by The Ministry of Education, Culture as part of the Government of Spain. E.M. was funded by Miguel Servet Fellowships (MS14/00046 and CPII19/00019) awarded by the Instituto de Salud Carlos III (ISCIII), Spanish Ministry of Science, Innovation and Universities, and Fondos FEDER. The funders had no role in study design, data collection and analysis, decision to publish, or preparation of the manuscript.

Institutional Review Board Statement: The study was conducted according to the guidelines of the Declaration of Helsinki and approved by the Ethics Committee of the Virgen de la Arrixaca University Clinical Hospital (protocol code 09/14, 29/09/2014 and 01/20, 28/01/2020).

Informed Consent Statement: The authors have obtained the informed consent of the patients and/or subjects mentioned in the article. The author for correspondence is in possession of this document. 
Data Availability Statement: The authors declare that they have followed the protocols of their work center on the publication of patient data and that all the patients included in the study have received sufficient information and have given their informed consent in writing to participate in that study.

Acknowledgments: The authors particularly thank all the participants for their generous collaboration. We want to particularly acknowledge the BioBank "Biobanco en Red de la Región de Murcia" (PT17/0015/0038) integrated in the Spanish National Biobanks Network (B.000859) for its collaboration. NELA Study Group: ME Candel-Torralba 1 , L Garcia-Marcos (PI) 1,2,4,18, MJ Gimenez-Banon ${ }^{1}$, A Martinez-Torres ${ }^{1,2,18}$, E Morales (PI) 1,3, V Perez-Fernandez 1,4,18, M SanchezSolis 1,2,4,18, A Nieto 1,5, MT Prieto-Sanchez 1,5, M Sanchez-Ferrer 1,5 , L Fernanez-Palacios 1,6, VP Gomez-Gomez ${ }^{1,6}$, C Martinez-Graciá ${ }^{1,6}$, P Peso-Echarri ${ }^{1,6}$, G Ros-Berruezo ${ }^{1,6}$, M Santaella-Pacua 11,6, A Gazquez 1,7, E Larque 1,7, MT Pastor-Fajardo 1,7, M Sanchez-Campillo 1,7, A Serrano-Munuera 1,7, M Zornoza-Moreno 1,7 , P Jimenez-Guerrero 1,8 , E Adomnei 1,9 , JJ Arense-Gonzalo 1,9 , J Mendiola 1,9 , F Navarro-Lafuente 1,9 , AM Torres-Cantero 1,9 , C Salvador-Garcia ${ }^{10}$, M Segovia-Hernández 1,11, G Yagüe-Guirao 1,11, PL Valero-Guillén 1,12, FV Aviles-Plaza 1,13, J Cabezas-Herrera 1,13, A Martinez-Lopez 1,13, M Martinez-Villanueva 1,13, JA Noguera-Velasco 1,13, A Franco-Garcia 1,14, AM Garcia-Serna ${ }^{1,14}$, T Hernandez-Caselles ${ }^{1,14,18}$, E Martin-Orozco ${ }^{1,14,18}$, M Norte-Muñoz ${ }^{1,14}$, M Canovas ${ }^{1,14}$, E Cantero-Cano ${ }^{1}$, T de Diego 1,14 , JM Pastor 1,14, RA Sola-Martínez 1,14, A EstebanGil ${ }^{1,17}$, JT Fernández-Breis ${ }^{1,15}$, MV Alcántara ${ }^{16}$, S Hernández ${ }^{16}$, C López-Soler ${ }^{16}{ }^{1}$ Biomedical Research Institute of Murcia, IMIB-Arrixaca, Murcia, Spain; ${ }^{2}$ Paediatric Respiratory Unit, “Virgen de la Arrixaca" Children's University Clinical Hospital, University of Murcia, Spain; ${ }^{3}$ Department of Public Health Sciences, University of Murcia, Spain; ${ }^{4}$ Department of Paediatrics, University of Murcia, Spain; ${ }^{5}$ Obstetrics \& Gynaecology Service, “Virgen de la Arrixaca" University Clinical Hospital, University of Murcia, Spain; ${ }^{6}$ Food Science and Technology Department, Veterinary Faculty of Veterinary, University of Murcia, Spain; ${ }^{7}$ Department of Physiology, Faculty of Biology, Campus Mare Nostrum. University of Murcia, Spain; ${ }^{8}$ Regional Atmospheric Modelling Group, Department of Physics, University of Murcia, Spain; ${ }^{9}$ Department of Public Health Sciences, University of Murcia, Spain; ${ }^{10}$ Microbiology Service, General University Hospital Consortium, University of Valencia, Spain; ${ }^{11}$ Microbiology Service, University Clinical Hospital "Virgen de la Arrixaca", University of Murcia, Spain; ${ }^{12}$ Microbiology and Genetics Department, University of Murcia, Spain; ${ }^{13}$ Molecular Therapy and Biomarkers Research Group, Clinical Analysis Service, University Clinical Hospital "Virgen de la Arrixaca", University of Murcia, Spain; ${ }^{14}$ Department of Biochemistry and Molecular Biology B and Immunology, University of Murcia, Spain; ${ }^{15}$ Department of Informatics and Systems, University of Murcia, Spain; ${ }^{16}$ Paediatric and Adolescent Clinical Psychology University Research Group (GUIIA-PC), University of Murcia, Spain; ${ }^{17}$ Foundation for Healthcare Training \& Research of the Region of Murcia (FFIS); ${ }^{18}$ Network of Asthma and Adverse and Allergic Reactions (ARADyAL).

Conflicts of Interest: The authors declare the non-existence of any type of conflict of interest.

\section{References}

1. Reijnders, I.F.; Mulders, A.G.M.G.J.; Van Der Windt, M.; Steegers, E.A.P.; Steegers-Theunissen, R.D.S.P.M. The impact of periconceptional maternal lifestyle on clinical features and biomarkers of placental development and function: A systematic review. Hum. Reprod. Update 2019, 25, 72-94. [CrossRef]

2. Yamamoto, J.M.; Kellett, J.E.; Balsells, M.; García-Patterson, A.; Hadar, E.; Solà, I.; Gich, I.; Van der Beek, E.M.; CastañedaGutiérrez, E.; Heinonen, S.; et al. Gestational diabetes mellitus and diet: A systematic review and meta-analysis of randomized controlled trials examining the impact of modified dietary interventions on maternal glucose control and neonatal birth weight. Diabetes Care 2018, 41, 1346-1361.

3. Kibret, K.T.; Chojenta, C.; Gresham, E.; Tegegne, T.K.; Loxton, D. Maternal dietary patterns and risk of adverse pregnancy (hypertensive disorders of pregnancy and gestational diabetes mellitus) and birth (preterm birth and low birth weight) outcomes: A systematic review and meta-analysis. Public Health Nutr. 2019, 22, 506-520. [CrossRef]

4. Martin, C.L.; Sotres-Alvarez, D.; Siega-Riz, A.M. Maternal Dietary Patterns during the Second Trimester Are Associated with Preterm Birth. J. Nutr. 2015, 145, 1857-1864. [CrossRef]

5. Chen, X.; Zhao, D.; Mao, X.; Xia, Y.; Baker, P.N.; Zhang, H. Maternal dietary patterns and pregnancy outcome. Nutrients 2016, 8, 351. [CrossRef]

6. Castro-Rodriguez, J.A.; Ramirez-Hernandez, M.; Padilla, O.; Pacheco-Gonzalez, R.M.; Pérez-Fernández, V.; Garcia-Marcos, L. Effect of foods and Mediterranean diet during pregnancy and first years of life on wheezing, rhinitis and dermatitis in preschoolers. Allergol. Immunopathol. 2016, 44, 400-409. [CrossRef] 
7. Chatzi, L.; Garcia, R.; Roumeliotaki, T.; Basterrechea, M.; Begiristain, H.; Iñiguez, C.; Vioque, J.; Kogevinas, M.; Sunyer, J. Mediterranean diet adherence during pregnancy and risk of wheeze and eczema in the first year of life: INMA (Spain) and RHEA (Greece) mother-child cohort studies. Br. J. Nutr. 2013, 110, 2058-2068. [CrossRef] [PubMed]

8. Garcia-Marcos, L.; Castro-Rodriguez, J.A.; Weinmayr, G.; Panagiotakos, D.B.; Priftis, K.N.; Nagel, G. Influence of Mediterranean diet on asthma in children: A systematic review and meta-analysis. Pediatr. Allergy Immunol. 2013, 24, 330-338. [CrossRef]

9. Simopoulos, A.P. The importance of the omega-6/omega-3 fatty acid ratio in cardiovascular disease and other chronic diseases. Exp. Biol. Med. 2008, 233, 674-688. [CrossRef] [PubMed]

10. Willers, S.M.; Wijga, A.H.; Brunekreef, B.; Kerkhof, M.; Gerritsen, J.; Hoekstra, M.O.; De Jongste, J.C.; Smit, H.A. Maternal food consumption during pregnancy and the longitudinal development of childhood asthma. Am. J. Respir. Crit. Care Med. 2008, 178, 124-131. [CrossRef] [PubMed]

11. Chu, S.; Yu, H.; Chen, Y.; Chen, Q.; Wang, B.; Zhang, J. Periconceptional and Gestational Exposure to Antibiotics and Childhood Asthma. PLoS ONE 2015, 10, e0140443. [CrossRef]

12. Calvani, M.; Alessandri, C.; Sopo, S.M.; Panetta, V.; Pingitore, G.; Tripodi, S.; Zappalà, D.; Zicari, A.M. Consumption of fish, butter and margarine during pregnancy and development of allergic sensitizations in the offspring: Role of maternal atopy. Pediatr. Allergy Immunol. 2006, 17, 94-102. [CrossRef] [PubMed]

13. Miyake, Y.; Sasaki, S.; Tanaka, K.; Hirota, Y. Consumption of vegetables, fruit, and antioxidants during pregnancy and wheeze and eczema in infants. Allergy 2010, 65, 758-765. [CrossRef] [PubMed]

14. Nurmatov, U.; Devereux, G.; Sheikh, A. Nutrients and foods for the primary prevention of asthma and allergy: Systematic review and meta-analysis. J. Allergy Clin. Immunol. 2011, 127, 724-733. [CrossRef] [PubMed]

15. Zhang, Y.; Lin, J.; Fu, W.; Liu, S.; Gong, C.; Dai, J. Mediterranean diet during pregnancy and childhood for asthma in children: A systematic review and meta-analysis of observational studies. Pediatr. Pulmonol. 2019, 54, ppul.24338. [CrossRef]

16. Carlos, S.; De La Fuente-Arrillaga, C.; Bes-Rastrollo, M.; Razquin, C.; Rico-Campà, A.; Martínez-González, M.; Ruiz-Canela, M. Mediterranean Diet and Health Outcomes in the SUN Cohort. Nutrients 2018, 10, 439. [CrossRef]

17. Esposito, K.; Maiorino, M.I.; Bellastella, G.; Chiodini, P.; Panagiotakos, D.; Giugliano, D. A journey into a Mediterranean diet and type 2 diabetes: A systematic review with meta-analyses. BMJ Open 2015, 5, e008222. [CrossRef]

18. Martinez-Lacoba, R.; Pardo-Garcia, I.; Amo-Saus, E.; Escribano-Sotos, F. Mediterranean diet and health outcomes: A systematic meta-review. Eur. J. Public Health 2018, 28, 955-961. [CrossRef]

19. Widmer, R.J.; Flammer, A.J.; Lerman, L.O.; Lerman, A. The Mediterranean Diet, its Components, and Cardiovascular Disease. Am. J. Med. 2015, 128, 229-238. [CrossRef]

20. Witlox, W.J.A.; van Osch, F.H.M.; Brinkman, M.; Jochems, S.; Goossens, M.E.; Weiderpass, E.; White, E.; van den Brandt, P.A.; Giles, G.G.; Milne, R.L.; et al. An inverse association between the Mediterranean diet and bladder cancer risk: A pooled analysis of 13 cohort studies. Eur. J. Nutr. 2019, 1-10. [CrossRef] [PubMed]

21. Amati, F.; Hassounah, S.; Swaka, A.; Amati, F.; Hassounah, S.; Swaka, A. The Impact of Mediterranean Dietary Patterns During Pregnancy on Maternal and Offspring Health. Nutrients 2019, 11, 1098. [CrossRef]

22. Fundación Dieta Mediterránea What's the Mediterranean Diet?-Fundación Dieta Mediterranea. Available online: https: / / dietamediterranea.com/en/nutrition/ (accessed on 20 October 2020).

23. Olmedo-Requena, R.; Fernández, J.G.; Prieto, C.A.; Moreno, J.M.; Bueno-Cavanillas, A.; Jiménez-Moleón, J.J. Factors associated with a low adherence to a Mediterranean diet pattern in healthy Spanish women before pregnancy. Public Health Nutr. 2014, 17, 648-656. [CrossRef]

24. Trichopoulou, A.; Costacou, T.; Bamia, C.; Trichopoulos, D. Adherence to a Mediterranean diet and survival in a Greek population. N. Engl. J. Med. 2003, 348, 2599-2608. [CrossRef]

25. Olmedo-Requena, R.; González-Donquiles, C.; Dávila-Batista, V.; Romaguera, D.; Castelló, A.; de la Torre, A.J.M.; Amiano, P.; Dierssen-Sotos, T.; Guevara, M.; Fernández-Tardón, G.; et al. Agreement among mediterranean diet pattern adherence indexes: MCC-Spain study. Nutrients 2019, 11, 488. [CrossRef]

26. Vioque, J.; Navarrete-Muñoz, E.M.; Gimenez-Monzó, D.; García-De-La-Hera, M.; Granado, F.; Young, I.S.; Ramón, R.; Ballester, F.; Murcia, M.; Rebagliato, M.; et al. Reproducibility and validity of a food frequency questionnaire among pregnant women in a Mediterranean area. Nutr. J. 2013, 12, 26. [CrossRef]

27. U.S. Department of Agriculture (USDA), A.R.S. USDA National Nutrient Database for Standard Reference, Release 27; USDA: Washington, DC, USA, 2014.

28. Palma, I.; Farran, A.; C.D.C. d'Ensenyament, S. de N. i D. (CESNID). Tablas de Composición de Alimentos por Medidas Caseras de Consumo Habitual en España, 1st ed.; McGraw Hill Interamericana, Ed.; McGraw Hill Interamericana: Madrid, Spain, 2008; ISBN 8448160906.

29. Olivares, A.B.; Bernal, M.J.; Ros, G.; Martínez, C.; Periago, M.J. Quality of data on folic acid content in vegetables included in several Spanish Food Composition Tables and new data on their folate content. Nutr. Hosp. 2006, 21, 97-108. [PubMed]

30. Fung, T.T.; McCullough, M.L.; Newby, P.K.; Manson, J.E.; Meigs, J.B.; Rifai, N.; Willett, W.C.; Hu, F.B. Diet-quality scores and plasma concentrations of markers of inflammation and endothelial dysfunction. Am. J. Clin. Nutr. 2005, 82, 163-173. [CrossRef] [PubMed] 
31. Buckland, G.; Gonzalez, C.A.; Agudo, A.; Vilardell, M.; Berenguer, A.; Amiano, P.; Ardanaz, E.; Arriola, L.; Barricarte, A.; Basterretxea, M.; et al. Adherence to the Mediterranean Diet and Risk of Coronary Heart Disease in the Spanish EPIC Cohort Study. Am. J. Epidemiol. 2009, 170, 1518-1529. [CrossRef]

32. Trichopoulou, A.; Kouris-Blazos, A.; Wahlqvist, M.L.; Gnardellis, C.; Lagiou, P.; Polychronopoulos, E.; Vassilakou, T.; Lipworth, L.; Trichopoulos, D. Diet and overall survival in elderly people. BMJ 1995, 311, 1457. [CrossRef] [PubMed]

33. Chatzi, L.; Torrent, M.; Romieu, I.; Garcia-Esteban, R.; Ferrer, C.; Vioque, J.; Kogevinas, M.; Sunyer, J. Mediterranean diet in pregnancy is protective for wheeze and atopy in childhood. Thorax 2008, 63, 507-513. [CrossRef]

34. Chiuve, S.E.; Fung, T.T.; Rimm, E.B.; Hu, F.B.; McCullough, M.L.; Wang, M.; Stampfer, M.J.; Willett, W.C. Alternative Dietary Indices Both Strongly Predict Risk of Chronic Disease. J. Nutr. 2012, 142, 1009-1018. [CrossRef]

35. Lange, N.E.; Rifas-Shiman, S.L.; Camargo, C.A.; Gold, D.R.; Gillman, M.W.; Litonjua, A.A. Maternal dietary pattern during pregnancy is not associated with recurrent wheeze in children. J. Allergy Clin. Immunol. 2010, 126, 250. [CrossRef]

36. Domingo-Salvany, A.; Regidor, E.; Alonso, J.; Alvarez-Dardet, C. Proposal for a social class measure. Working Group of the Spanish Society of Epidemiology and the Spanish Society of Family and Community Medicine. Aten. Primaria 2000, 25, 350-363. [CrossRef]

37. RStudio Team (2020). RStudio: Integrated Development Environment for R; RStudio Team, PBC: Boston, MA, USA. Available online: http:/ / www.rstudio.com/ (accessed on 15 March 2021).

38. León-Muñoz, L.M.; Guallar-Castillón, P.; Graciani, A.; López-García, E.; Mesas, A.E.; Aguilera, M.T.; Banegas, J.R.; RodríguezArtalejo, F. Adherence to the Mediterranean Diet Pattern Has Declined in Spanish Adults. J. Nutr. 2012, 142, 1843-1850. [CrossRef] [PubMed]

39. Wesołowska, E.; Jankowska, A.; Trafalska, E.; Kałużny, P.; Grzesiak, M.; Dominowska, J.; Hanke, W.; Calamandrei, G.; Polańska, K. Sociodemographic, Lifestyle, Environmental and Pregnancy-Related Determinants of Dietary Patterns during Pregnancy. Int. J. Environ. Res. Public Health 2019, 16, 754. [CrossRef] [PubMed]

40. Moraes, M.M.; Oliveira, B.; Afonso, C.; Santos, C.; Miranda, R.C.; Rauber, F.; Levy, R.B.; Rodrigues, S. Mediterranean diet, sociodemographic factors and ultra-processed food consumption in Portugal. Eur. J. Public Health 2020, 30. [CrossRef]

41. De Castro, M.B.T.; Freitas Vilela, A.A.; De Oliveira, A.S.D.; Cabral, M.; De Souza, R.A.G.; Kac, G.; Sichieri, R. Sociodemographic characteristics determine dietary pattern adherence during pregnancy. Public Health Nutr. 2016, 19, 1245-1251. [CrossRef] [PubMed]

42. Northstone, K.; Emmett, P.; Rogers, I. Dietary patterns in pregnancy and associations with socio-demographic and lifestyle factors. Eur. J. Clin. Nutr. 2008, 62, 471-479. [CrossRef] [PubMed]

43. Chatzi, L.; Mendez, M.; Garcia, R.; Roumeliotaki, T.; Ibarluzea, J.; Tardón, A.; Amiano, P.; Lertxundi, A.; Iñiguez, C.; Vioque, J.; et al. Mediterranean diet adherence during pregnancy and fetal growth: INMA (Spain) and RHEA (Greece) mother-child cohort studies. Br. J. Nutr. 2012, 107, 135-145. [CrossRef]

44. Da Silva, R.; Bach-Faig, A.; Raidó Quintana, B.; Buckland, G.; Vaz De Almeida, M.D.; Serra-Majem, L. Worldwide variation of adherence to the Mediterranean diet, in 1961-1965 and 2000-2003. Public Health Nutr. 2009, 12, 1676-1684. [CrossRef] [PubMed]

45. Bédard, A.; Northstone, K.; John Henderson, A.; Shaheen, S.O. Mediterranean diet during pregnancy and childhood respiratory and atopic outcomes: Birth cohort study. Eur. Respir. J. 2020, 55. [CrossRef] [PubMed]

46. Alvarez Zallo, N.; Aguinaga-Ontoso, I.; Alvarez-Alvarez, I.; Marin-Fernandez, B.; Guillén-Grima, F.; Azcona-San Julián, C. Influence of the Mediterranean diet during pregnancy in the development of wheezing and eczema in infants in Pamplona, Spain. Allergol. Immunopathol. 2018, 46, 9-14. [CrossRef] [PubMed]

47. Maderuelo-Fernandez, J.A.; Recio-Rodríguez, J.I.; Patino-Alonso, M.C.; Pérez-Arechaederra, D.; Rodriguez-Sanchez, E.; GomezMarcos, M.A.; García-Ortiz, L. Effectiveness of interventions applicable to primary health care settings to promote Mediterranean diet or healthy eating adherence in adults: A systematic review. Prev. Med. 2015, 76, S39-S55. [CrossRef] [PubMed] 